\title{
A metered intake of milk following exercise and thermal dehydration restores whole-body net fluid balance better than a carbohydrate-electrolyte solution or water in healthy young men
}

\author{
Suzanne Seery ${ }^{1}$ and Philip Jakeman ${ }^{1,2 *}$ \\ ${ }^{1}$ Department of Physical Education and Sport Sciences, University of Limerick, Limerick V94 YDE9, Republic of Ireland \\ ${ }^{2}$ Human Science Research Unit, Centre for Interventions in Inflammation, Infection and Immunity, University of Limerick, \\ Limerick V94 YDE9, Republic of Ireland
}

(Submitted 18 November 2015 - Final revision received 23 June 2016 - Accepted 29 June 2016 - First published online 1 August 2016)

\section{Abstract}

Appropriate rehydration and nutrient intake in recovery is a key component of exercise performance. This study investigated whether the recovery of body net fluid balance (NFB) following exercise and thermal dehydration to $-2 \%$ of body mass (BM) was enhanced by a metered rate of ingestion of milk $(\mathrm{M})$ compared with a carbohydrate-electrolyte solution (CE) or water (W). In randomised order, seven active men (aged 26.2 (sD 6.1) years) undertook exercise and thermal dehydration to $-2 \%$ of BM on three occasions. A metered replacement volume of $\mathrm{M}, \mathrm{CE}$ or $\mathrm{W}$ equivalent to $150 \%$ of the BM loss was then consumed within $2-3 \mathrm{~h}$. NFB was subsequently measured for $5 \mathrm{~h}$ from commencement of rehydration. A higher overall NFB in M than CE $(P=0.001)$ and $\mathrm{W}(P=0.006)$ was observed, with no difference between $\mathrm{CE}$ and $\mathrm{W}(P=0 \cdot 69)$. After $5 \mathrm{~h}, \mathrm{NFB}$ in $\mathrm{M}$ remained positive $(+117$ (SD 122$) \mathrm{ml})$ compared with basal, and it was greater than $\mathrm{W}(-539$ (sD 390) $\mathrm{ml}, P=0.011)$ but not CE $(-381$ (sD 460) $\mathrm{ml}, P=0.077, d=1.6)$. Plasma osmolality $\left(\mathrm{P}_{\mathrm{osm}}\right.$ ) and $\mathrm{K}$ remained elevated above basal in $\mathrm{M}$ compared with $\mathrm{CE}$ and $\mathrm{W}$. The change in $\mathrm{P}_{\mathrm{osm}}$ was associated with circulating pre-provasopressin $\left(r_{s} 0 \cdot 348, P<0 \cdot 001\right)$, a biomarker of arginine vasopressin, but could not account fully for the augmented NFB in M compared with CE and W. These data suggest that a metered approach to fluid ingestion acts in synergy with the nutrient composition of $\mathrm{M}$ in the restoration of NFB following exercise and thermal dehydration.

\section{Key words: Rehydration: Metered fluid intake: Milk: Carbohydrate electrolyte: Net water balance}

Normal physiological and behavioural perturbation of net body water (fluid) balance changes daily total body water (TBW) by $<1 \%{ }^{(1)}$. The demands of physical activity perturb whole-body fluid balance and results in a net water deficit (dehydration) that may affect exercise tolerance and/or performance ${ }^{(2-4)}$. Physical activity accelerates the rate of substrate oxidation and the depletion of body energy stores. Particularly during intense exercise, the preferential use of carbohydrate as a substrate leads to accelerated use of muscle glycogen and an increase in branched chain amino acid oxidation by muscle that is inversely related to muscle glycogen content ${ }^{(5)}$. After exercise, amino acids, particularly the essential amino acids (EAA), are required in support of tissue repair and remodelling. A recovery beverage should, therefore, fulfil both fluid and nutrient requirements. Supported by evidence that milk can act as an effective rehydration fluid ${ }^{(6,7)}$, it is reasoned that the nutrient composition of milk offers a superior recovery fluid than water or carbohydrate-electrolyte solutions (CE).

A common, laboratory-based, experimental paradigm to investigate the optimal strategy for fluid replacement is to undertake prolonged (approximately $90 \mathrm{~min}$ ) exercise and thermal dehydration to a fixed decrease in body mass $(-2 \% \mathrm{BM})$, a surrogate of change in $\mathrm{TBW}^{(8,9)}$. The outcome of these studies recommends a fluid replacement regimen that requires the ingestion of a fluid volume equivalent to $150 \%$ of the $\mathrm{BM}$ loss during exercise to be consumed within $1 \mathrm{~h}$ after exercise $^{(10)}$. The volume of fluid equivalent to $150 \%$ of an approximately $2 \%$ loss in BM for an $80 \mathrm{~kg}$ male approximates to 2.5 litres, which, when ingested in bolus mode over a short time (i.e. $1 \mathrm{~h}$ ), results in enhanced diuresis and failure to restore net fluid balance (NFB) within $4-6 \mathrm{~h}^{(8,9,11)}$. The rate and magnitude of fluid retention following exercise and thermal dehydration is enhanced by the addition of electrolytes ${ }^{(11-13)}$, carbohydrate $^{(14-17)}$ and protein ${ }^{(18-21)}$ affecting singly, or in combination, the inter-related processes of gastric emptying, intestinal absorption and retention. Addition of electrolytes, carbohydrate and protein may also fulfil the requirement to replenish body reserves and recovery of muscle glycogen.

Recent evidence suggests that a 'metered' approach to fluid replacement post exercise is a more effective strategy ${ }^{(22)}$.

Abbreviations: AVP, arginine vasopressin; BM, body mass; CE, carbohydrate-electrolyte solution; CTproAVP, pre-provasopressin; M, milk; NFB, net fluid balance; $\mathrm{P}_{\mathrm{osm}}$, plasma osmolality; $\mathrm{W}$, water.

* Corresponding author: Professor P. Jakeman, fax +3536120 2841, email phil.jakeman@ul.ie 
A metered fluid intake has greater ecological validity for the athlete, but whether the presence of electrolytes or macronutrients in the rehydration fluid would act in synergy with a metered fluid intake to improve body NFB following exercise is not known. In this study, exercise and thermal dehydration to $-2 \% \mathrm{BM}$ was used to examine net body fluid balance over a 5 -h period following metered replacement of three rehydration fluids of constant volume, equivalent to $150 \%$ of the exercise-induced BM loss. Plain water (W) was used as the control fluid against which a proprietary CE and low-fat milk (M) was compared. CE is purported to be optimised for postexercise restoration of fluid and carbohydrate and is a popular form of replenishment fluid following exercise ${ }^{(23)}$. M was chosen for the enhanced electrolyte $(\mathrm{K})$ and macro-nutrient (carbohydrate, protein and fat) composition and healthier nutrient profile compared with proprietary CE products. The primary aim was to investigate whether NFB following exercise and thermal dehydration to $-2 \% \mathrm{BM}$ was enhanced by a metered rate of ingestion of $\mathrm{M}$ or $\mathrm{CE}$ compared with $\mathrm{W}$. A secondary aim was to investigate whether the composition of the rehydration fluid was sufficient to affect a change in circulating pre-provasopressin (CTproAVP) - a novel biomarker of the potent antidiuretic arginine vasopressin (AVP) and signature of an augmented osmoregulatory response.

\section{Methods}

\section{Subjects}

All procedures were carried out in accordance with the ethical standards outlined in the most recent version of the Declaration of Helsinki, and procedures involving human subjects were approved by the Faculty of Education \& Health Sciences Research Ethics Committee (EHSREC10/45), University of Limerick. Subjects were provided with full details of the study, and queries related to the study were addressed before a written statement of informed consent was obtained. Seven healthy men (age 26.2 (sD 6.1) years, height 1.79 (sD 0.08) m, BM 86.4 (SD 11.5) $\mathrm{kg}$ and body fat 21.4 (SD 4.5 ) \%) volunteered to participate in the investigation. At the time of the study, all were engaged in regular physical activity ( $>3 \mathrm{~h} /$ week) but were not accustomed to exercise in a warm environment. Because of the nature of the investigation, those with known lactose intolerance were excluded.

\section{Experimental protocol}

All subjects attended two habituation and three experimental trials. In the $24 \mathrm{~h}$ preceding each trial, subjects were instructed to abstain from alcohol and strenuous physical activity. Subjects also recorded a weighed food and fluid intake and physical activity diary and were asked to replicate these patterns of dietary intake and physical activity before each subsequent trial. In the $24 \mathrm{~h}$ preceding the first trial, subjects provided a record of weighed food and fluid intake and a diary of physical activity. Subjects were instructed to repeat these behaviours before subsequent trials. All trials commenced in the morning, normally 07.00 hours, and followed a standardised protocol.
On the evening preceding a trial day, subjects were instructed to fast from midnight and to consume $500 \mathrm{ml}$ of water $1 \mathrm{~h}$ before arrival at the laboratory. On arrival, subjects completed a subjective feelings questionnaire and provided a urine and venous blood sample. Height, to the nearest $0 \cdot 1 \mathrm{~cm}$ (Seca 213 Stadiometer; Seca), BM, to the nearest $0 \cdot 1 \mathrm{~kg}$, TBW (bioelectric impedance analysis; MC-180MA; Tanita UK Ltd) and body composition (dual energy X-ray absorptiometry; Lunar iDXA ${ }^{\mathrm{TM}}$; GE Healthcare) were measured during the first habituation trial. Measurement of $\mathrm{BM}$ and body water content was repeated on all subsequent trial days. At the second habituation trial, subjects completed a familiarisation session on a cycle ergometer (Monark Ergomedic 874E; Monark Exercise AB) to confirm the steady-state work rate to be undertaken during the dehydration phase of the three experimental trials. The experimental trials were randomised and separated by $7 \mathrm{~d}$. The experimental trial proceeded as follows: after provision of a urine sample, an $18 \mathrm{G}$ cannula was inserted into a superficial vein located at the antecubital fossa and a basal (resting) blood sample was drawn. Subjects then consumed a standardised breakfast comprising $40 \mathrm{~g}$ of cornflakes, full-fat milk $(200 \mathrm{ml})$, a breakfast bar (37g; Kellogg's ${ }^{\circledR}$ Nutri-Grain ${ }^{\circledR}$; Kellogg Company) and plain water $(100 \mathrm{ml}) 1 \mathrm{~h}$ before the dehydration phase. Further blood samples were drawn post exercise and at $1,2,3,4$ and $5 \mathrm{~h}$ of the rehydration phase.

\section{Dehydration phase}

Before entering an environmental chamber maintained at 30 (SD $1 \cdot 1)^{\circ} \mathrm{C}$ and 58 (SD 8) \% relative humidity, subjects voided their bladder and BM was measured. Subjects then undertook a continuous bout of cycle exercise for $50 \mathrm{~min}$, towelled dry and reweighed. Subjects returned to the environmental chamber to continue exercise for 10-min intervals until a BM loss of approximately $1.8 \%$ was achieved. Having showered, dried thoroughly and voided their bladder subjects were reweighed to determine total BM loss during the dehydration phase. Expired air was collected and analysed for the rate of $\mathrm{VO}_{2}$ and carbon dioxide production $\left(\mathrm{VCO}_{2}\right)$ by indirect calorimetry (AMIS 2000; Innovision A/S) from which estimates of the rate of energy expenditure, carbohydrate and fat metabolism were calculated ${ }^{(24)}$.

\section{Rehydration phase}

Rehydration commenced $25 \mathrm{~min}$ after the end of the dehydration phase and lasted for $5 \mathrm{~h}$. For this phase, subjects remained seated in a laboratory $\left(20.5(\mathrm{SD} 1.2)^{\circ} \mathrm{C}, 35\right.$ (SD 8$) \%$ relative humidity) and, other than the rehydration fluid, no food or drink was consumed. The rehydration fluid was randomly assigned and administered to subjects at room temperature $\left(18-20^{\circ} \mathrm{C}\right)$. The composition of the rehydration fluids, that is, milk (0.1\% skimmed milk; Glanbia Consumer Foods Ireland Plc; trial M), CE (Powerade; Coca Cola Ltd; trial CE) and water (Centra; Musgrave Retail Partners Ireland; trial W), is provided in Table 1.

Subjects ingested a volume (litres) equivalent to $150 \%$ of the BM loss (kg). Using a metered protocol, $1000 \mathrm{ml}$ was provided 
Table 1. Energy density, osmolality, protein, carbohydrate and fat content, sodium and potassium concentration of the rehydration fluids (Mean values and standard deviations)

\begin{tabular}{|c|c|c|c|c|c|c|}
\hline & \multicolumn{2}{|c|}{$M$} & \multicolumn{2}{|c|}{ CE } & \multicolumn{2}{|c|}{ W } \\
\hline & Mean & $\mathrm{SD}$ & Mean & SD & Mean & SD \\
\hline Energy density (kJ/l) & 1450 & 0 & 700 & 0 & 0 & 0 \\
\hline Osmolality (mosmol/kg) & 280 & 2 & 299 & 2 & 11 & 1 \\
\hline Protein $(g / l)$ & 33 & 0 & 0 & 0 & 0 & 0 \\
\hline Carbohydrate $(\mathrm{g} / \mathrm{l})$ & 50 & 0 & 39 & 0 & 0 & 0 \\
\hline Fat $(\mathrm{g} / \mathrm{l})$ & 1 & 0 & 0 & 0 & 0 & 0 \\
\hline $\mathrm{Na}(\mathrm{mmol} / \mathrm{l})$ & $17 \cdot 9$ & 0 & $21 \cdot 7$ & 0 & 0.7 & 0 \\
\hline
\end{tabular}

M, milk; CE, carbohydrate-electrolyte solution; W, water.

to be ingested within the first $30 \mathrm{~min}$ and $500 \mathrm{ml}$ every $30 \mathrm{~min}$ thereafter until the required volume of fluid was consumed. Subjects were allowed $15 \mathrm{~min}$ in which to consume each aliquot. All subjects completed the ingestion of the required volume of all fluids within the specified time. Subjects were instructed to empty their bladder as completely as possible at the end of each hour. The volume of urine provided was measured, and a $5 \mathrm{ml}$ aliquot was retained for analysis. Any additional urine produced during the recovery period was collected and added to the bolus produced at the end of each hour. Subjective feelings relating to hydration (thirst, hunger, bloatedness, mouth taste, alertness, headache, tiredness and refreshment) were assessed by $100 \mathrm{~mm}$ visual analogue scales. Subjective responses for hydration were provided for the basal state, following the completion of the dehydration phase and at the end of each hour during the rehydration phase. Subjective responses relating to drink taste (visual appeal, palatability, aftertaste, sweetness and saltiness) were obtained for $2 \mathrm{~h}$ of the rehydration period.

\section{Biochemical analysis}

Whole-blood samples were analysed immediately after collection for $\mathrm{Na}$ and $\mathrm{K}$ concentration by ion-selective potentiometry (I-STAT $^{\circledR}$; Abbott Laboratories). Intra-assay CV using control solutions was $<1 \%$ for both $\mathrm{Na}$ and $\mathrm{K}$. Inter-assay $\mathrm{CV}$ was $<1.5 \%$ for $\mathrm{Na}$ and $<11 \%$ for $\mathrm{K}$, using baseline samples. Plasma and urine osmolality was measured by freezing-point depression (Advanced Micro-Osmometer Model 3220; Advanced Instruments Inc.). The intra-assay $\mathrm{CV}$ for $\mathrm{P}_{\mathrm{osm}}$ was $1.2 \%$. CTproAVP was measured in a single batch with a commercial sandwich immunoluminometric assay (B.R.A.H.M.S LUMItest CTproAVP; B.R.A.H.M.S AG). The lower detection limit of this assay was $0.4 \mathrm{pM}$, and the functional assay sensitivity $(<20 \%$ inter-assay CV) was $<1 \mathrm{pM}$. The intra-assay CV was $<10 \%$.

\section{Statistical analysis}

Unless stated otherwise, data are presented as means and standard deviations. Statistical analysis was performed within the Statistical Package for the Social Sciences (SPSS, 21.0; SPSS Inc.). Data were checked for normality of distribution by Shapiro-Wilk test. Data containing two independent factors were analysed by two-factor (time $\times$ trial) repeated-measures
ANOVA. Variables containing one factor were analysed using a one-factor repeated-measures ANOVA. Bonferroni-adjusted paired sample Student's $t$ test was used to compare the means and locate significant differences. The $95 \%$ level of confidence was the criterion of statistical difference $(P<0 \cdot 05)$. Where statistical significance marginally exceeded 0.05 the effect size, Cohen's $d$ was calculated to indicate the standardised difference between means. Friedman's test and post hoc Wilcoxon's signed-rank tests were used to compare differences between trials for non-parametric data relating to subjective responses rated by visual analogue scales.

\section{Results}

\section{Basal hydration status}

No difference was observed in basal BM, hydration status or blood electrolyte concentration for each trial (Table 2), indicating that the subjects complied fully with the prescribed pre-experimental protocol.

\section{Dehydration phase}

The dehydration protocol achieved a BM loss of -1.84 (sD 0.28) $\mathrm{kg}(\mathrm{W}),-1.86$ (SD 0.37) $\mathrm{kg}(\mathrm{CE})$ and -1.82 (sD 0.28) kg (M), which did not differ between trials $(P=0.84)$. This corresponded to $-2 \cdot 2$ (sD $0 \cdot 2) \%(W),-2 \cdot 2$ (sD $0 \cdot 2) \%(C E)$ and $-2 \cdot 1$ (SD 0.2$) \%(M)$ loss of the subjects' basal BM. The duration of exercise required to achieve this was not different between trials ( $P=0 \cdot 16$ ): 94 (sD 17) $\mathrm{min}(\mathrm{W}), 93$ (sD 11) $\mathrm{min}(\mathrm{CE})$ and 101 (SD 16) min (M). Estimates of energy expenditure, carbohydrate and fat oxidation are provided in Table 3.

\section{Rehydration phase}

Aligned with the outcome of the dehydration phase, the volume of fluid ingested during the rehydration phase was not significantly different between trials $(P=0 \cdot 84) ; 2764$ (sD 416) $\mathrm{ml}(\mathrm{W})$, 2796 (sD 556) $\mathrm{ml}$ (CE) and 2732 (sD 426) $\mathrm{ml}$ (M). Significantly lower mean hourly urine volume was observed in the rehydration phase in $\mathrm{M}$ compared with $\mathrm{CE}$ and $\mathrm{W}$ (time $\times$ trial, $P=0.01)$, resulting in a lower cumulative urine volume in $\mathrm{M}$ compared with $\mathrm{CE}(P=0.013)$ and $\mathrm{W}(P=0.007)$ but no difference between $\mathrm{CE}$ and $\mathrm{W}(P=0 \cdot 68)$ (Fig. 1(a)). At $5 \mathrm{~h}$, total 
Table 2. Body mass, total body water, blood and urine osmolality and electrolyte concentration at basal (Mean values and standard deviations)

\begin{tabular}{|c|c|c|c|c|c|c|c|}
\hline & \multicolumn{2}{|c|}{ M } & \multicolumn{2}{|c|}{ CE } & \multicolumn{2}{|c|}{ W } & \multirow[b]{2}{*}{$P^{*}$} \\
\hline & Mean & SD & Mean & SD & Mean & SD & \\
\hline Body mass $(\mathrm{kg})$ & $85 \cdot 6$ & 11.5 & $86 \cdot 2$ & $11 \cdot 6$ & $85 \cdot 7$ & 11.0 & 0.56 \\
\hline Total body water (litres) & $50 \cdot 0$ & 4.46 & $49 \cdot 8$ & 4.23 & $50 \cdot 0$ & $4 \cdot 17$ & 0.91 \\
\hline Plasma osmolality (mosmol/kg) & 286 & 3.4 & 287 & $3 \cdot 2$ & 288 & 4.4 & 0.33 \\
\hline Plasma $\mathrm{Na}(\mathrm{mmol} / \mathrm{l})$ & $140 \cdot 7$ & $1 \cdot 7$ & $140 \cdot 6$ & 2.9 & 139.9 & $2 \cdot 0$ & 0.55 \\
\hline Plasma K (mmol/l) & 3.9 & 0.1 & 4.0 & 0.3 & 3.9 & 0.3 & 0.95 \\
\hline
\end{tabular}

M, milk; CE, carbohydrate-electrolyte solution; $\mathrm{W}$, water.

* $P$ values for the difference between groups analysed by univariate ANOVA.

Table 3. Estimate of energy expenditure, carbohydrate and fat oxidation during the exercise and dehydration phase (Mean values and standard deviations)

\begin{tabular}{|c|c|c|c|c|c|c|c|}
\hline & \multicolumn{2}{|c|}{$M$} & \multicolumn{2}{|c|}{ CE } & \multicolumn{2}{|c|}{ W } & \multirow[b]{2}{*}{$P^{*}$} \\
\hline & Mean & SD & Mean & $\mathrm{SD}$ & Mean & SD & \\
\hline Total energy (kJ) & 3730 & 663 & 3440 & 559 & 3877 & 950 & 0.44 \\
\hline Carbohydrate oxidation (g) & 167 & 31 & 149 & 28 & 171 & 40 & 0.36 \\
\hline Fat oxidation (g) & 28 & 6 & 29 & 5 & 31 & 9 & 0.63 \\
\hline
\end{tabular}

M, milk; CE, carbohydrate-electrolyte solution; W, water.

${ }^{*} P$ values for the difference between groups analysed by univariate ANOVA.

urine volume in M (794 (sD 99) $\mathrm{ml})$ was lower than W (1429 $(\mathrm{sD} 131) \mathrm{ml})(P=0.018)$ but not CE (1314 (sD 164) ml) $(P=0.057$; $d=1 \cdot 7)$. Percentage fluid retention reflected these differences between trials: 71 (sD 4)\% (M), 52 (SD 16)\% (CE, $P=0 \cdot 048)$ and 47 (sD 15) \% (W, $P=0 \cdot 014$ ).

Whole-body NFB was calculated from the change in BM (reflecting the loss of fluid by sweating), fluid ingested and urine produced. No significant difference in NFB was observed between trials following dehydration $(P=0.84)$, but a significant difference in the time course of change in NFB was observed between trials (time $\times$ trial, $P=0.003$ ) in the rehydration phase (Fig. 1(b)). A higher overall NFB was maintained throughout the rehydration phase in $\mathrm{M}$ than $\mathrm{CE}(P=0.001)$ and $\mathrm{W}(P=0.006)$, with no difference between $\mathrm{CE}$ and $\mathrm{W}(P=0 \cdot 69)$. At $2 \mathrm{~h}$ into rehydration, NFB was positive compared with basal in $\mathrm{M}$ and significantly greater than CE $(P=0.031)$ but not W $(P=0.09$, $d=1 \cdot 38)$. At $3 \mathrm{~h}, \mathrm{NFB}$ remained positive in $\mathrm{M}$ and greater than W $(P=0.019)$ but not CE $(P=0.069, d=1.21)$, and this trend continued to $5 \mathrm{~h}$, at which point NFB in $\mathrm{M}$ remained positive compared with basal and greater than W $(P=0 \cdot 011)$ but not $\mathrm{CE}$ $(P=0.077, d=1 \cdot 6)$.

\section{Plasma osmolality and pre-provasopressin}

The relationship between plasma osmolality $\left(\mathrm{P}_{\mathrm{osm}}\right)$ and CTproAVP is reported in Fig. 2. Spearman's rank correlation revealed a moderate, but statistically significant $(P<0.0001)$, association between $\mathrm{P}_{\mathrm{osm}}$ and serum CTproAVP concentration (Fig. 2(a)) and between the change in CTproAVP induced by a change in $\mathrm{P}_{\mathrm{osm}}$ (Fig. 2(b)). A threshold of effect on serum CTproAVP is observed when $\mathrm{P}_{\text {osm }}$ increased above approximately $290 \mathrm{mosmol} / \mathrm{kg}$, which approximates to approximately $3 \mathrm{mosmol} / \mathrm{kg}$ increase in $\mathrm{P}_{\mathrm{osm}}$ from basal values.

$\mathrm{P}_{\mathrm{osm}}$ was similar for all trials at basal (288 (sD 4.5) mosmol $/ \mathrm{kg}$, W; 287 (sD 3.2) mosmol $/ \mathrm{kg}, \quad \mathrm{CE} ; 288$ (sD 3.4) mosmol $/ \mathrm{kg}, \quad \mathrm{M}$, $P=0.33)$ and increased following dehydration, with no significant difference between trials $(P=0 \cdot 22)$ (online Supplementary Fig. S1(a)). A significant difference in the time course of change in $\mathrm{P}_{\mathrm{osm}}$ during rehydration was observed between trials (time $\times$ trial, $P=0.003$ ) (Fig. 3(a)), remaining elevated above basal levels in trial $\mathrm{M}$ compared with trial CE and $\mathrm{W}(P=0 \cdot 001)$. At $1 \mathrm{~h}, \mathrm{P}_{\mathrm{osm}}$ remained elevated above basal in $\mathrm{M}$ compared with $\mathrm{CE}(P=0.016)$ but not $\mathrm{W}(P=0.051$, $d=1.74)$; at $2 \mathrm{~h}, \mathrm{M}$ was greater than $\mathrm{CE}(P=0.002)$ and $\mathrm{W}$ $(P=0.002)$; at $3 \mathrm{~h}, \mathrm{M}$ was greater that $\mathrm{W}(P=0.04)$ but not $\mathrm{CE}$ $(P=0.052, d=1.13)$; at $4 \mathrm{~h}, \mathrm{M}$ was greater than $\mathrm{CE}(P=0.046)$ and $\mathrm{W}(P=0.001)$ and $\mathrm{CE}$ was greater than $\mathrm{W}(P=\cdot 037)$. At the end of the 5-h rehydration period, $\mathrm{P}_{\text {osm }}$ returned to within basal levels for M 288 (sD 3.9) mosmol/kg, CE 287 (sD 2.6) mosmol $/ \mathrm{kg}$ and $\mathrm{W} 286(\mathrm{sD} 1.5) \mathrm{mosmol} / \mathrm{kg}$, with no difference $(P=0 \cdot 13)$ between trials.

No significant difference in the time course of change in serum CTproAVP was observed between trials (time $\times$ treatment, $P=0.96$ ) (online Supplementary Fig. S1(b)). Serum CTproAVP was similar for all trials at basal (4.6 (SD 1.2) pmol/1, W; 4.3 (sD 1.6) pmol/1, CE; 4.1 (sD 1.8) pmol/l, M, $P=0.73$ ) and increased approximately 5 -fold from basal in response to dehydration to 29.1 (sD 26.9) $\mathrm{pmol} / \mathrm{l}$ (W), 23.8 (SD 13.5) $\mathrm{pmol} / \mathrm{l}$ (CE) and 27.8 (sD 13.4) pmol/l (M) $(P=0.72)$ (Fig. 3(b)). CTproAVP decreased during rehydration to values that were not significantly different from basal at $1 \mathrm{~h}(P>0.05)$, and remained unchanged thereafter. 
(a)

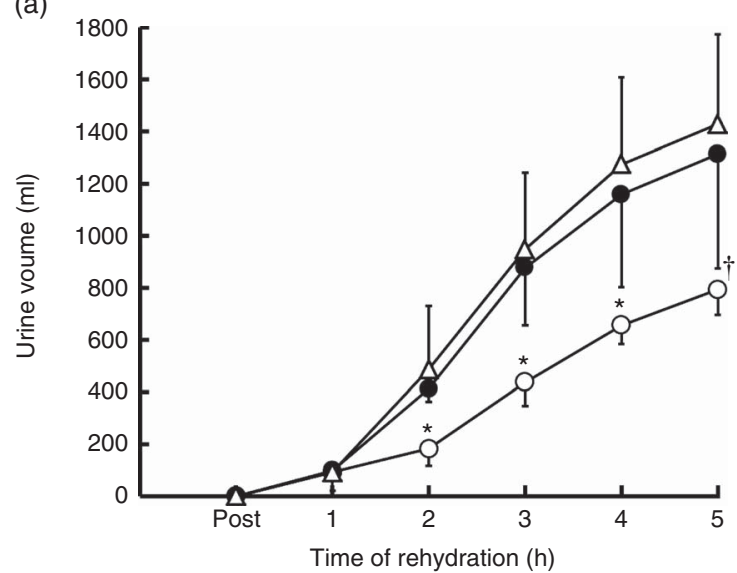

(b)

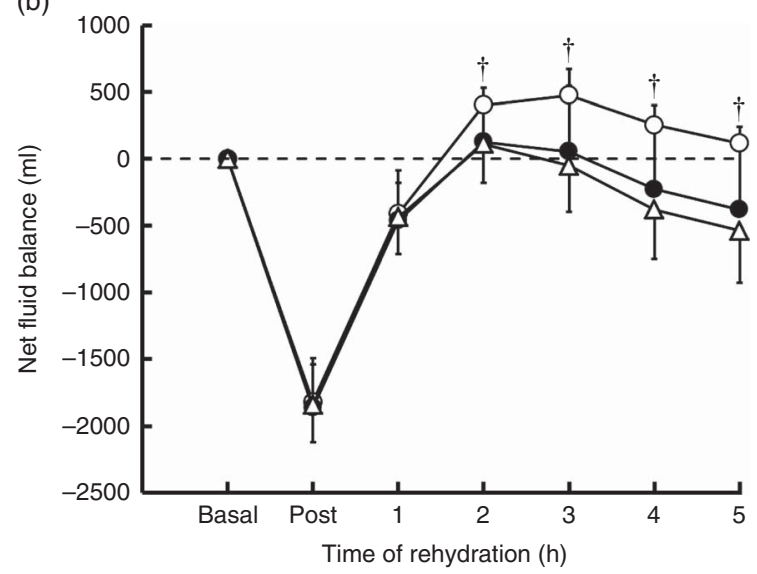

Fig 1. Urinary volume (a) and net fluid balance (b) over the course of the experimental trials. Values are means and standard deviations represented by vertical bars. *Value of milk (M) significantly different from carbohydrateelectrolyte solution (CE) and water (W) $(P<0.05)$. $†$ Value of $\mathrm{M}$ is significantly different from $\mathrm{W}(P<0.05)$. $-\mathrm{O}-$, Trial $\mathrm{M} ;-\bullet-$, trial $\mathrm{CE} ; \triangle \triangle$, trial $\mathrm{W}$.

\section{Plasma electrolytes}

Plasma Na was similar for all trials at basal (140 (SD 2.0) mmol/l, W; 141 (sD 2.9) $\mathrm{mmol} / \mathrm{l}$, CE; 141 (sD 1.7 ) mmol/l, M, $P=0.55$ ), and no significant difference in plasma $\mathrm{Na}$ in response over the duration of the experiment was observed between trials (time $\times$ trial, $P=0.22$ ) (online Supplementary Fig. S2(a)) (Fig. 4(a)). Basal plasma K was similar for all trials $(3.93$ (sD 0.30) mmol/l, W; 3.96 (sD 0.32 ) $\mathrm{mmol} / \mathrm{l}, \mathrm{CE} ; 3.91$ (sD 0.15$) \mathrm{mmol} / \mathrm{l}, \mathrm{M}, P=0.95$ ), increasing by 0.25 (sD 0.22$) \mathrm{mmol} / 1$ following dehydration, with no significant difference in response between trials $(P=0.71)$ (online Supplementary Fig. S2(a)). A significant difference in plasma $\mathrm{K}$ during rehydration was observed between trials (time $\times$ treatment; $P<0.001$ ), remaining elevated above basal for the 5 -h rehydration period in $\mathrm{M}$ and greater than in trial $\mathrm{CE}(P=0.006)$ and W $(P=0.008)$, with no difference in response between CE and $\mathrm{W}(P=0 \cdot 11)$. At $1 \mathrm{~h}$ into rehydration, $\mathrm{K}$ remained significantly elevated above basal in M compared with CE $(P=0.001)$ but not $\mathrm{W}(P=0.063, d=1.74)$; at $2 \mathrm{~h}, \mathrm{M}$ was greater than $\mathrm{CE}(P=0.005)$ and $\mathrm{W}(P=0.021)$; at $3 \mathrm{~h}, \mathrm{M}$ was greater than $\mathrm{CE}(P=0.024)$ and $\mathrm{W}(P=0.013)$; at $4 \mathrm{~h}, \mathrm{M}$ was greater than $\mathrm{CE}(P=0.004)$ and (a)

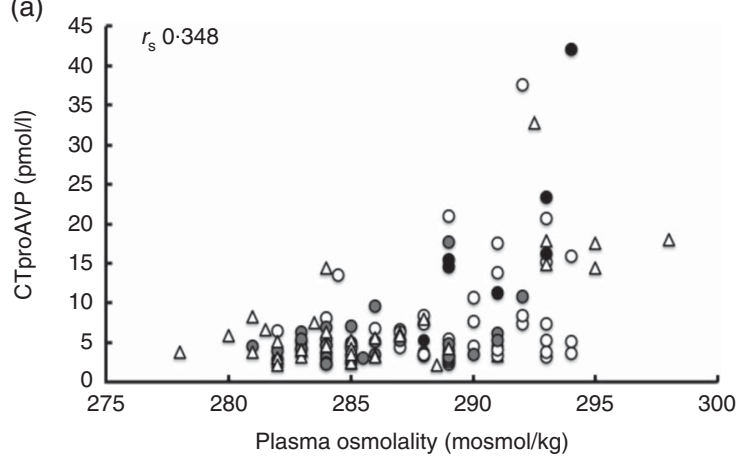

(b)

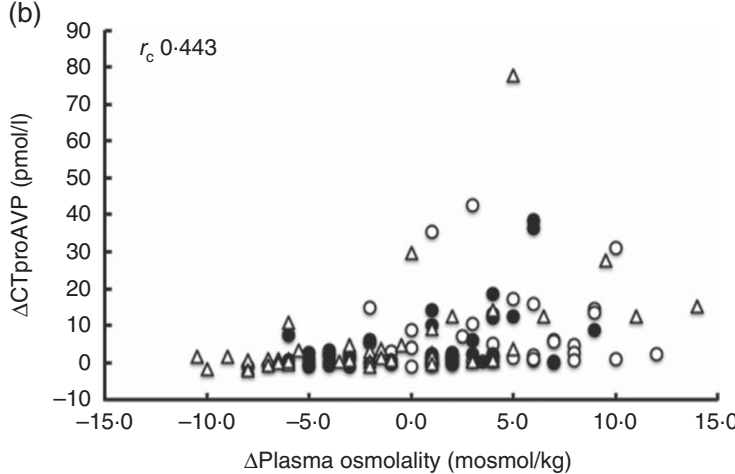

Fig 2. Relationship between (a) plasma osmolality and pre-provasopressin (CTproAVP) concentration and (b) change in pre-provasopressin ( $\triangle \mathrm{CTproAVP}$ ) measured over the course of the experimental trials shown as scatter plots. $r_{s}$, Spearman's rank correlation coefficient ( $n$ 126); $\bigcirc$, trial milk; 0 , trial carbohydrate-electrolyte solution; $\Delta$, trial water.

W $(P=0.022)$ and greater in M compared with CE $(P=0.003)$ but not $\mathrm{W}(P=0.88)$ at $5 \mathrm{~h}$ (Fig. 4(b)).

\section{Subjective feelings of hydration and drink acceptance}

There was a marked increase in perceived thirst score immediately post exercise for all trials, although no overall difference in change in thirst perception scores was observed between test drinks during the rehydration period $(P=0.53)$. Ingestion of a rehydration fluid reduced the feeling of thirst from a pooled mean of 81 (SD 6) to 45 (SD 4) mm and gradually returned to basal feelings of thirst by the end of the 5-h rehydration period for all three trials: M 51 (SD 26) $\mathrm{mm}$ $(P=0.67)$; CE 50 (sD 24) $\mathrm{mm}(P=0.79)$; and $\mathrm{W}$ trials 51 (sD 27) $\mathrm{mm}(P=0 \cdot 39)$. Participants scored mouth taste lowest in $\mathrm{W}$ trial (14 (sD 4) mm) compared with $\mathrm{CE}(35$ (sD 13) $\mathrm{mm})$ $(P=0.034)$ and $\mathrm{M}(44(\mathrm{sD} 8) \mathrm{mm})(P=0 \cdot 013)$. Perceived feeling of hunger differed between test drinks during rehydration (time $\times$ trial $)(P=0.037)$, with a lower overall mean score in the $\mathrm{M}$ trial 51 (SD 9) $\mathrm{mm}$ compared with W 79 (SD 9) $\mathrm{mm}$, and CE 66 (sD 14) mm. Similar perceived levels of bloatedness $(P=0.15)$, alertness $(P=0.28)$, tiredness $(P=0.063)$, headache $(P=0.16)$ and level of refreshment $(P=0.06)$ were reported for all rehydration fluids. Subjective feelings associated with drink taste were analysed for the 2nd hour of fluid ingestion. There was no difference in perceived visual appeal $(P=0.54)$, palatability $(P=0.57)$ or aftertaste $(P=0.06)$ 
(a)

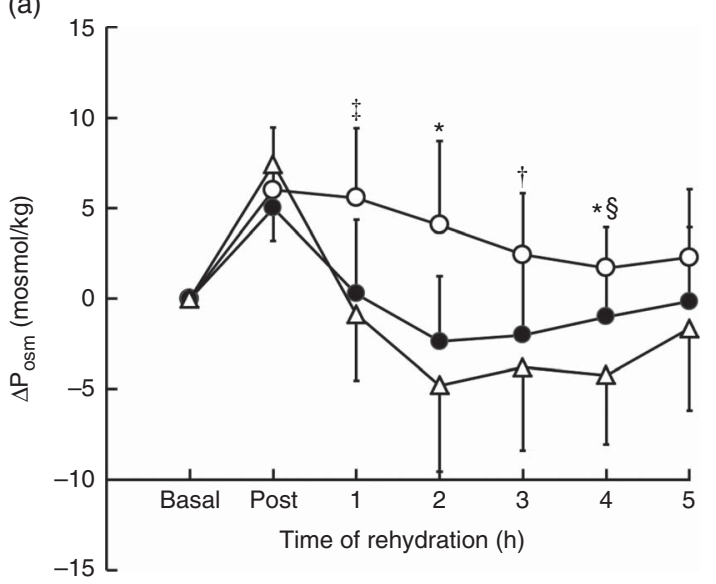

(b)

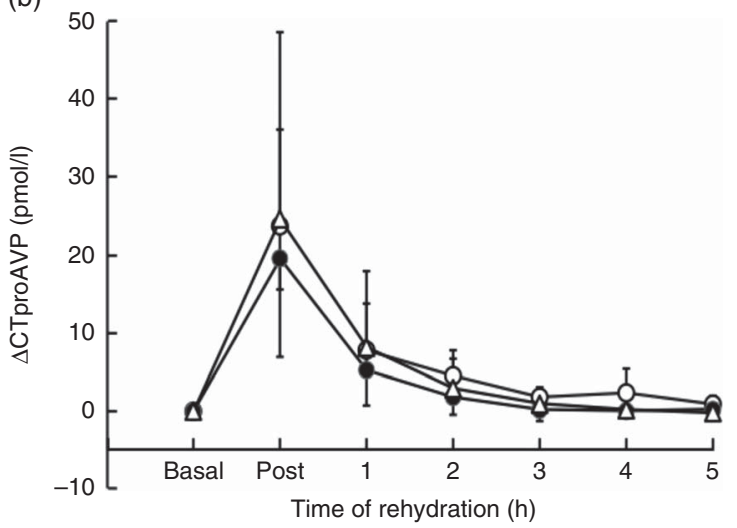

Fig 3. Change in plasma osmolality $\left(\Delta \mathrm{P}_{\mathrm{osm}}\right)$ (a) and serum pre-provasopressin $(\triangle C T p r o A V P)(b)$ from basal values over the course of the experimental trials. Values are the means and standard deviations represented by vertical bars. * Value of milk (M) significantly different from carbohydrate-electrolyte solution (CE) and water $(\mathrm{W})(P<0.05)$. $†$ Value of $\mathrm{M}$ significantly different from $\mathrm{W}(P<0.05)$. $\ddagger$ Value of $\mathrm{M}$ significantly different from $\mathrm{CE}(P<0.05)$. § Value of $\mathrm{CE}$ significantly different from $\mathrm{W}(P<0.05)$. $\_-$, Trial $\mathrm{M} ;-\bullet-$, trial $\mathrm{CE} ; \_\_$, trial $\mathrm{W}$.

between trials. There was a higher perceived sweetness for CE compared with $\mathrm{M}(P=0.048)$ and $\mathrm{W}(P=0.018)$. Perceived saltiness also scored highest in the CE trial - 29 (sD 28) $\mathrm{mm}$ compared with M 18 (sD 30) $\mathrm{mm}(P=0.046)$ and W 3 (sD 3) $\mathrm{mm}$ $(P=0.028)$ trials, although overall scores were low across trials.

\section{Energy and substrate intake in comparison with expenditure}

A comparison of the total energy, carbohydrate and fat intake provided in the rehydration phase for $M$ and $C E$ is provided in Table 4 . The mean total energy provision was approximately 2-fold greater for $\mathrm{M}$ than $\mathrm{CE}$, the difference being less because of carbohydrate (approximately $40 \%$ greater in $\mathrm{M}$ ) than for the additional protein and fat provided in M. Relative to the mean estimates of energy expenditure, M provided $106 \%$ of total energy, $82 \%$ of total carbohydrate and $10 \%$ of total fat oxidised during exercise. In comparison, $\mathrm{CE}$ provided $57 \%$ of total energy and $73 \%$ of total carbohydrate used during exercise. (a)

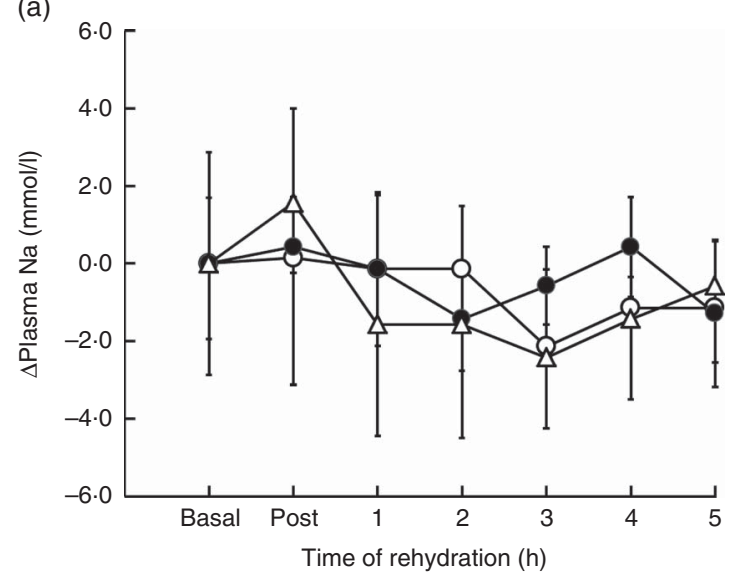

(b)

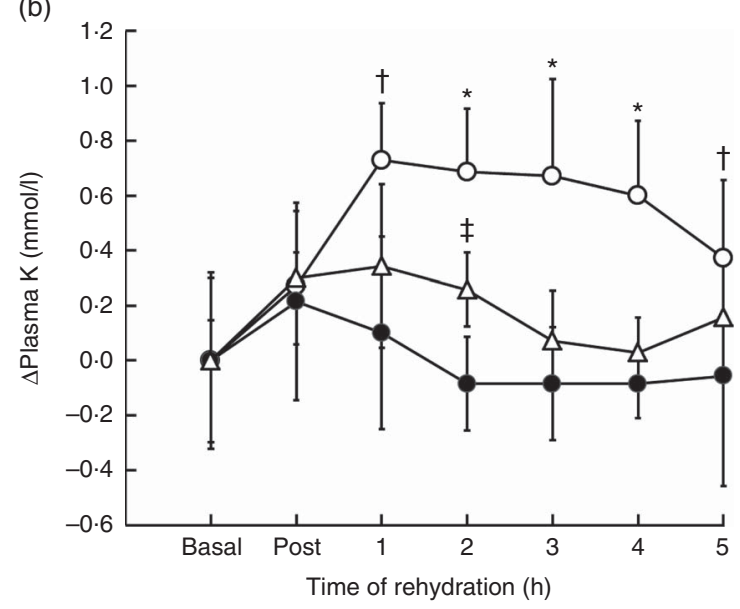

Fig 4. Change in plasma sodium (a) and plasma potassium (b) from basal values over the course of the experimental trials. Values are the means and standard deviations represented by vertical bars. * Value of milk (M) significantly different from carbohydrate-electrolyte solution (CE) and water $(\mathrm{W})(P<0.05)$. $†$ Value of $\mathrm{M}$ significantly different from $\mathrm{CE}(P<0.05)$. $\ddagger$ Value of $\mathrm{CE}$ significantly different from W $(P<0.05)$. $\multimap-$, Trial $\mathrm{M} ;-\bullet-$, trial $\mathrm{CE} ; \triangle \backsim$, trial W.

Table 4. Estimate of energy, carbohydrate and fat provided during the rehydration phase

(Mean values and standard deviations)

\begin{tabular}{|c|c|c|c|c|c|}
\hline & \multicolumn{2}{|c|}{$M$} & \multicolumn{2}{|c|}{ CE } & \multirow[b]{2}{*}{$P^{*}$} \\
\hline & Mean & SD & Mean & SD & \\
\hline Total energy (kJ) & 3962 & 234 & 1958 & 147 & $<0.001$ \\
\hline Carbohydrate $(\mathrm{g})$ & 137 & 8 & 109 & 8 & $<0.001$ \\
\hline Fat (g) & $2 \cdot 7$ & 0.2 & 0 & 0 & $<0.001$ \\
\hline Protein (g) & 90 & $5 \cdot 3$ & 0 & 0 & $<0.001$ \\
\hline
\end{tabular}

M, milk; CE, carbohydrate-electrolyte solution.

* $P$ values for the difference between groups analysed by paired sample $t$ test.

\section{Discussion}

The purpose of a metered rate of fluid ingestion was to optimise the inter-related processes of gastric emptying, intestinal absorption and retention of the rehydration fluid. The rate of gastric emptying is related to rate of fluid ingestion that is 
modulated by the energy density and osmolality of the fluid, with energy density exerting a greater influence than osmolality ${ }^{(25,26)}$. M contains approximately double the energy density compared with the $\mathrm{CE}$, and rehydration studies using fluids containing milk protein confirm a slowing in the rate of gastric emptying and a delay in the rate of intestinal water absorption into the circulation ${ }^{(26)}$. Once fluid is absorbed and released into the circulation, the magnitude and time course of change in $\mathrm{P}_{\mathrm{osm}}$ is a key determinant of water retention. The loss of plasma volume and associated increase in $\mathrm{P}_{\mathrm{osm}}$ during dehydration was associated with a 5-fold increase in CTproAVP, a marker of the antidiuretic hormone AVP. CTproAVP is produced during synthesis of mature AVP in a 1:1 ratio as a stable peptide, sensitive to measurement by specific immunoassay and representative of the antidiuretic effect of $\mathrm{AVP}^{(27)}$. Analysed over all samples and all time points, a highly significant association between $\mathrm{P}_{\mathrm{osm}}$ and CTproAVP $\left(r_{s} 0.348 ; P<0.001\right)$ was observed. The mean increase in CTproAVP across all trials in response to exercise and thermal-induced dehydration was 5-fold the basal level but, as shown in Fig. 2, plasma CTproAVP concentration at a given osmolality varied widely between individuals, particularly at osmolalities above $287 \mathrm{mosmol} / \mathrm{kg}$, and highlights the polygenetic variability of this response ${ }^{(28,29)}$. However, despite the continued elevation in $\mathrm{P}_{\mathrm{osm}}$ in the early phase of rehydration in M, CTproAVP returned to basal levels within $1 \mathrm{~h}$ of rehydration in all trials.

An increase in AVP is predicted to promote a compensatory change in renal water conservation and decrease in water excretion subsequently potentiated by ingestion of the rehydration fluid. Ingestion of $\mathrm{W}$ caused the largest decrease in $\mathrm{P}_{\mathrm{osm}}$ (approximately $12 \mathrm{mosmol} / \mathrm{l}$ ) from 295 (sD $2 \cdot 2 \mathrm{mosmol} / \mathrm{l}$ ) following dehydration to 283 (sD 2.9) mosmol/l at $2 \mathrm{~h}$ rehydration. The response to ingestion of $\mathrm{CE}$ did not differ significantly from $\mathrm{W}$, but the outcome in $\mathrm{M}$ was to maintain an elevated $\mathrm{P}_{\mathrm{osm}}$ of +5 mosmol/l during the early phase of rehydration (Fig. 3). The maintenance of an elevated $\mathrm{P}_{\mathrm{osm}}$ in $\mathrm{M}$ might be predicted by the protein content in $\mathrm{M}$, the higher energy density resulting in a decrease in the rate of gastric emptying ${ }^{(26)}$. In addition, the protein in $\mathrm{M}$ could augment the osmotic/oncotic pressure via an increase in plasma albumin and/or post ingestion increase in plasma amino acid concentration ${ }^{(19,21)}$. Plasma albumin is the major contributor to oncotic pressure that trends towards an increase over time when milk-based proteins are added to a carbohydrate beverage ${ }^{(30)}$. On the basis of pilot data (unpublished results), total free amino acid concentration following ingestion of $\mathrm{M}$ or $\mathrm{CE}$ increases approximately $500 \mu \mathrm{mol} / 1$ in $\mathrm{M}$ and decreases approximately $400 \mu \mathrm{mol} / 1$ in CE, $1 \mathrm{~h}$ post ingestion. Acting independently, the change in plasma albumin and amino acid concentration of this magnitude may be too low to alter serum osmolality, but could act in synergy to augment NFB.

Analysed across all trials, no effect of the experimental protocol on plasma $\mathrm{Na}$ was observed (online Supplementary Fig. S2(a). Considering the strong influence that $\mathrm{Na}$ and chloride, its principal anion, exerts on $\mathrm{P}_{\mathrm{osm}}$, these data are perplexing, possibly reflecting the relative imprecision offered by the point-of-care platform of measurement. In contrast, a significant increase in plasma $\mathrm{K}$ was observed over the rehydration phase in $M$ (online Supplementary Fig. S2(b)). The maintenance of plasma $\mathrm{K}$ in $\mathrm{M}$ relative to $\mathrm{CE}$ and $\mathrm{W}$ could have contributed to water retention via its effect on the reninangiotensin-aldosterone axis. Controlled infusion of potassium chloride results in an increase in circulating aldosterone; the response is most sensitive to an increase in plasma $\mathrm{K}$ within a range of $0 \cdot 1-0.5 \mathrm{mmol} / \mathrm{l}^{(31)}-$ that is, of comparable magnitude to that observed in the present study.

The main considerations for an athlete in recovery from exercise are the replacement of fluid and electrolytes lost in sweat, repletion of body energy reserves, principally muscle and liver glycogen, and the provision of nutrient support to the regeneration or adaptation of skeletal muscle ${ }^{(32)}$. In recovery, M provided $106 \%$ of total energy and $82 \%$ of total carbohydrate oxidised during exercise compared with $57 \%$ of total energy and $73 \%$ of total carbohydrate provided by $\mathrm{CE}$. The recommended intake of carbohydrate in recovery is $1.0-1.2 \mathrm{~g} / \mathrm{kg}$ per $\mathrm{h}$ to be consumed at frequent intervals during the first $4-6 \mathrm{~h}$ post exercise $^{(32)}$. The mean intake for $\mathrm{M}(1.6 \mathrm{~g} / \mathrm{kg}$ per $5 \mathrm{~h})$ was higher than CE $(1.3 \mathrm{~g} / \mathrm{kg}$ per $5 \mathrm{~h})$, but both rehydration solutions fell short of the recommended recovery rate for carbohydrate intake. Although protein intake in recovery may enhance glycogen resynthesis, particularly in the early $(0-2 \mathrm{~h})$ phase or when the carbohydrate intake is sub-optimal ${ }^{(33)}$, the primary effect of adding protein to a recovery fluid, particularly when consumed in close proximity to exercise, would be to stimulate skeletal muscle protein synthesis (MPS) ${ }^{(34)}$. The mean protein intake in $\mathrm{M}$ was $90 \mathrm{~g}$, equivalent to $1.1 \mathrm{~g} / \mathrm{kg} \mathrm{BM}$, and greater than the recommended intake of protein to stimulate MPS post exercise $^{(32)}$. Furthermore, the EAA composition of milk proteins approximates to $50 \%$. EAA, particularly leucine, are the main nutrient regulators of MPS, which lends support to the use of milk protein as a natural and effective source of protein for recovery ${ }^{(35)}$. However, in practice, an athlete would probably use a recovery beverage as a supplement to habitual dietary intake, and the present investigation did not address the effect of habitual dietary intake in combination with a recovery beverage, and it is probable that solid food and beverage intake would influence the temporal pattern of restoration of body $\mathrm{NFB}^{(36)}$. However, when time between exercise bouts is short $(<6 \mathrm{~h})$, the potential for gastrointestinal disturbance in the following training session is an important consideration in the recovery plan and a liquid recovery strategy may be more acceptable.

Finally, gastrointestinal disturbance is a relevant consideration during recovery post exercise, particularly when large volumes of nutrient-dense fluids, such as $\mathrm{M}$, are consumed. Although published evidence is lacking ${ }^{(37)}$, a metered rate of fluid ingestion is considered to reflect, more closely, ad libitum drinking patterns, avoiding over-distension of the stomach and potential for negative gastrointestinal effects, such as bloatedness. Subjects were screened for lactose intolerance, as those with lactose intolerance generally can only tolerate relatively small dose of lactose approximately $12 \mathrm{~g}$ (approximately $200 \mathrm{ml}$ of milk) ${ }^{(38)}$. However, large lactose loads can result in gastrointestinal disturbances such as bloating and diarrhoea that may be further exacerbated in those with undiagnosed lactase deficiency. Possibly reflecting the lower 
rate of lactose load, the subjective feeling of bloatedness post ingestion of milk in the first $2 \mathrm{~h}$ of rehydration in this study scored relatively low $(\leq 34 \mathrm{~mm})$ compared with previous studies using a non-metered approach ${ }^{(5)}$.

In conclusion, it was possible to demonstrate a significant advantage in the restoration of body NFB over a 5-h period following exercise and thermal dehydration to $-2 \% \mathrm{BM}$ by a metered replacement of $\mathrm{M}$ compared with $\mathrm{CE}$ or $\mathrm{W}$. Consumed as the sole recovery diet, neither $\mathrm{M}$ nor $\mathrm{CE}$ provided optimal nutrition for recovery. However, the protein component of $\mathrm{M}$, essentially absent in CE and $\mathrm{W}$, may further enhance glycogen resynthesis and promote MPS. In addition, the minerals (Ca, P, Zn, I) and vitamins (A, E, B group vitamins) in $M$ that are not present in $\mathrm{CE}$ contribute to micro-nutrient requirements of the athlete.

\section{Acknowledgements}

The authors would like to thank Gavin Connolly, Alexandra Cremona, Katie Hughes, Robert Davies and Beate Gilson for their assistance in the data collection and the subjects for providing their time and commitment to the project.

This work was supported by the National Dairy Council, Ireland. The National Dairy Council, Ireland had no role in the design, analysis or writing of this article.

S. S. and P. J. conceived the study design. S. S. conducted the study and managed the data collection. S. S. and P. J. undertook the data analysis and co-authored the manuscript.

Supported by National Dairy Council Research Scholarship to S. S.

\section{Supplementary material}

For supplementary material/s referred to in this article, please visit http://dx.doi.org/10.1017/S0007114516002907

\section{References}

1. Cheuvront SN, Ely BR, Kenefick RW, et al. (2010) Biological variation and diagnostic accuracy of dehydration assessment markers. Am J Clin Nutr 92, 565-573.

2. Goulet DB (2013) Effect of exercise-induced dehydration on endurance performance: evaluating the impact of exercise protocols on outcomes using a meta-analytic procedure. $\mathrm{BrJ}$ Sports Med 47, 679-686.

3. Cheuvront SN \& Kenefick RW (2014) Dehydration: physiology, assessment, and performance effects. Compr Physiol 4, 257-285.

4. Wall BA, Watson G, Peiffer JJ, et al. (2015) Current hydration guidelines are erroneous: dehydration does not impair exercise performance in the heat. Br J Sports Med 49, 1077-1083.

5. Kasperek GJ \& Snider RD (1987) Effect of exercise intensity and starvation on activation of branched-chain keto acid dehydrogenase by exercise. Am J Physiol 252, E33-E37.

6. Shirreffs SM, Watson P \& Maughan RJ (2007) Milk as an effective post-exercise rehydration drink. Br J Nutr 98, 173-180.

7. Watson P, Love TD, Maughan RJ, et al. (2008) A comparison of the effects of milk and a carbohydrate-electrolyte drink on the restoration of fluid balance and exercise capacity in a hot, humid environment. Eur J Appl Physiol 104, 633-642.
8. Shirreffs SM, Taylor AJ, Leiper JB, et al. (1996) Post-exercise rehydration in man: effects of volume consumed and drink sodium content. Med Sci Sports Exerc 28, 1260-1271.

9. Shirreffs SM \& Maughan RJ (1998) Volume repletion after exercise-induced volume depletion in humans: replacement of water and sodium losses. Am J Physiol 274, F868-F875.

10. Sawka MN, Burke LM, Eichner ER, et al. (2007) American college of sports medicine position stand. Exercise and fluid replacement. Med Sci Sports Exerc 39, 377-390.

11. Nose H, Mack GW, Shi X, et al. (1988) Role of osmolality and plasma volume during rehydration in humans. $J$ Appl Physiol (1985) 65, 325-331.

12. Maughan RJ, Shirreffs SM \& Leiper JB (1994) Post-exercise rehydration in man: effects of electrolyte addition to ingested fluids. Eur J Appl Physiol Occup Physiol 69, 209-215.

13. Merson SJ, Maughan RJ \& Shirreffs SM (2008) Rehydration with drinks differing in sodium concentration and recovery from moderate exercise-induced hypohydration in man. Eur J Appl Physiol 103, 585-594.

14. Nielsen B, Sjogaard G, Ugelvig J, et al. (1986) Fluid balance in exercise dehydration and rehydration with different glucoseelectrolyte drinks. Eur J Appl Physiol Occup Physiol 55, 318-325.

15. Evans GH, Shirreffs SM \& Maughan RJ (2009) Postexercise rehydration in man: the effects of osmolality and carbohydrate content of ingested drinks. Nutrition 25, 905-913.

16. Osterberg KL, Pallardy SE, Johnson RJ, et al. (2010) Carbohydrate exerts a mild influence on fluid retention following exercise-induced dehydration. J Appl Physiol (1985) 108, $245-250$

17. Clayton DJ, Evans GH \& James LJ (2014) Effect of drink carbohydrate content on postexercise gastric emptying, rehydration, and the calculation of net fluid balance. Int $J$ Sport Nutr Exerc Metab 24, 79-89.

18. Seifert J, Harmon J \& DeClercq P (2006) Protein added to a sports drink improves fluid retention. Int J Sport Nutr Exerc Metab 16, 420-429.

19. James LJ, Clayton D \& Evans G H (2011) Effect of milk protein addition to a carbohydrate-electrolyte rehydration solution ingested after exercise in the heat. Br J Nutr 105, 393-399.

20. James LJ, Evans GH, Madin J, et al. (2013) Effect of varying the concentrations of carbohydrate and milk protein in rehydration solutions ingested after exercise in the heat. Br J Nutr 110, 1285-1291.

21. James LJ, Mattin L, Aldiss P, et al. (2014) Effect of whey protein isolate on rehydration after exercise. Amino Acids $\mathbf{4 6}$, $1217-1224$.

22. Jones EJ, Bishop PA, Green JM, et al. (2010) Effects of metered versus bolus water consumption on urine production and rehydration. Int J Sport Nutr Exerc Metab 20, 39-44.

23. Euromonitor (2014) Sports and energy drinks in Ireland. http://www.euromonitor.com/sports-and-energy-drinks-inireland/report (accessed September 2014).

24. Frayn KN (1983) Calculation of substrate oxidation rates in vivo from gas exchange. J App Physiol Respir Environ Exerc Physiol 55, 628-634.

25. Vist GE \& Maughan RJ (1995) The effect of osmolality and carbohydrate content on the rate of gastric emptying of liquids in man. J Physiol 486, 523-531.

26. Calbet JA \& MacLean DA (1997) Role of caloric content on gastric emptying in humans. J Physiol 498, 553-559.

27. Balanescu S, Kopp P, Gaskill MB, et al. (2011) Correlation of plasma copeptin and vasopressin concentrations in hypo-, iso-, and hyperosmolar states. I Clin Endocrinol Metab 96, 1046-1052. 
28. Cheuvront SN, Kenefick RW, Charkoudian N, et al. (2013) Physiologic basis for understanding quantitative dehydration assessment. Am J Clin Nutr 97, 455-462.

29. Zerbe RL, Miller JZ \& Robertson GL (1991) The reproducibility and heritability of individual differences in osmoregulatory function in normal human subjects. J Lab Clin Med 117, 51-59.

30. Hobson R \& James L (2015) The addition of whey protein to a carbohydrate-electrolyte drink does not influence postexercise rehydration. J Sports Sci 33, 77-84.

31. Himathongkam T, Dluhy RG \& Williams GH (1974) Potassium-aldosterone-renin interrelationships. I Clin Endocrinol Metab 41, 153-159.

32. Thomas DT, Erdman KA \& Burke LM (2016) Position of the Academy of Nutrition and Dietetics, Dietitians of Canada, and the American College of Sports Medicine: Nutrition and Athletic Performance. J Acad Nutr Diet 116, 501-528.

33. Ivy JL, Goforth HW Jr, Damon BM, et al. (2002) Early postexercise muscle glycogen recovery is enhanced with a carbohydrate-protein supplement. J Appl Physiol (1985) 93, $1337-1344$.
34. Tipton KD, Rasmussen BB, Miller SL, et al. (2001) Timing of amino acid-carbohydrate ingestion alters anabolic response of muscle to resistance exercise. Am J Physiol Endocrinol Metab 281, E197-E206.

35. Tipton KD, Elliott TA, Cree MG, et al. (2007) Stimulation of net muscle protein synthesis by whey protein ingestion before and after exercise. Am J Physiol Endocrinol Metab 292, E71-E76.

36. Maughan RJ, Leiper JB \& Shirreffs SM (1977) Factors influencing the restoration of fluid and electrolyte balance after exercise in the heat. Br J Sports Med 31, 175-182.

37. Wong SH, Williams C, Simpson M, et al. (1998) Influence of fluid intake pattern on short-term recovery from prolonged, submaximal running and subsequent exercise capacity. J Sports Sci 16, 143-152.

38. National Centre for Biotechnology Information (2010) Lactose intolerance and health, Evidence Reports/Technology Assessments No. 192. Bethesda, MD. http://www.ncbi.nlm. nih.gov/books/NBK44616/ (accessed September 2014). 